\title{
On the Anisotropic Impact Behavior of an Additively Manufactured AISi10Mg Alloy in Different Heat Treatment Conditions
}

\author{
Maverick Giovagnoli, Marialaura Tocci, Annalisa Fortini, Mattia Merlin, Matteo Ferroni, and Annalisa Pola
}

\author{
Submitted: 8 July 2021 / Revised: 10 December 2021 / Accepted: 5 February 2022 / Published online: 22 February 2022
}

\begin{abstract}
The present work deals with the anisotropic high-strain rate behavior of laser-powder bed fusion (L-PBF) produced AISi10Mg alloy in different heat treatment conditions. Impact specimens were produced with different orientations towards building platform and U-notch positions to assess the anisotropic properties. Besides the as-built material, several heat treatments were considered, including annealing, standard T6, hot isostatic pressing (HIP), HIP plus T6, and a recently proposed T6 at high pressure. The high-strain rate behavior was investigated by conducting Charpy impact tests, while material characterization was performed by scanning electron microscopy and $x$-ray diffraction. Results show that as-built and annealed alloys display significant anisotropic impact properties, whereas samples heat-treated at high temperatures generally have more consistent behavior. A coupled microstructural and fractographic investigation highlights that mitigation of anisotropy descends from the recovery of microstructural heterogeneity of the Si phase after heat treatment at high temperatures. This does not happen for both grain morphology or crystallographic structure, which are not significantly altered after the heat treatment. The present study aims to fill the gap in the literature regarding the anisotropic high-strain rate behavior of additively manufactured Al alloys and provide useful insights for mitigation of anisotropy by heat treatment.
\end{abstract}

Keywords additive manufacturing, AlSi10Mg, anisotropy, heat treatment, impact properties

\section{Introduction}

The need for a decrease in energy consumption challenges the automotive, aerospace and marine industries to a systematic weight reduction of corresponding components. Additive manufacturing (AM) technologies are thus considered extremely promising due to the possibility of topology optimization (Ref 1) and the realization of lattice structures (Ref 2). Al alloys also represent a further advantage in light-weight applications. In particular, Al-Si alloys are suitable for AM processes due to their optimum processability, with the AlSi10Mg alloy being the most widely employed. It receives significant attention thanks to its tailorable microstructure, which enables ultrafine microstructural features (Ref 3), alteration of crystallographic texture (Ref 4$)$, and strengthening by aging treatment $(\operatorname{Ref} 5,6)$.

Maverick Giovagnoli, Annalisa Fortini, and Mattia Merlin, Department of Engineering, University of Ferrara, via Saragat 1, 44122 Ferrara, Italy; Marialaura Tocci and Annalisa Pola, Department of Mechanical and Industrial Engineering, University of Brescia, via Branze 38, 25123 Brescia, Italy; Matteo Ferroni, Department of Civil Engineering, Architecture, Land, Environment and of Mathematics (DICATAM), University of Brescia, via Branze 43, 25123 Brescia, Italy; and CNR-IMM, Institute for Microelectronics and Microsystems, Via P. Gobetti 101, 40129 Bologna, Italy. Contact e-mail: marialaura.tocci@unibs.it.
Among the process-related drawbacks, AM produced Al alloys suffer from structural anisotropy (Ref 7-11), which is a significant limitation in conventional engineering applications that generally require isotropic and consistent properties. However, anisotropy is not limited to Al alloys (Ref 7-13), and generally affects both metals and alloys which are processed by AM techniques.

Carrol et al. (Ref 14) and Simonelli et al. (Ref 15) attributed the different ductility of an L-PBF processed Ti-6Al-4V alloy in the longitudinal and transverse directions to the morphological texture of $\beta$-grains. Hitzler et al. (Ref 16) found that the best strength and Young's modulus of an L-PBF produced 316L stainless steel are reached under a $45^{\circ}$ offset between the layer and loading direction. Takaichi et al. (Ref 17) ascribed the mechanical anisotropy of a CrCoMo alloy to a combination of morphological and crystallographic textures of primary columnar grains.

Concerning Al alloys, Hitzler et al. (Ref 11) demonstrated that the tensile properties of an AM produced AlSi10Mg alloy strongly depend on the specimen orientation. For instance, Young's modulus and tensile strength each range between 62.6 and 72.9 GPa and 314-399 MPa. Tang et al. (Ref 9) found that AlSi10Mg specimens exhibit better tensile performances when produced horizontally rather than vertically and attributed this behavior to the micro-residual stress created by the different thermal expansion of Al matrix and Si network. Di Giovanni et al. (Ref 7) ascribed the anisotropic high-cycle fatigue crack growth behavior of the AlSi10Mg alloy in the as-built state to the easy fracture path offered by melt pool boundaries and residual stresses. After T6 heat treatment, homogenization of microstructure and reduction of residual stresses mitigate the dependence of the crack growth rate on specimen orientation. 
Similarly, De Menezes et al. (Ref 12) explained differences in fracture toughness of an L-PBF produced A357 alloy, ascribing the microstructural heterogeneities as the leading cause of anisotropy. Conversely, Rao et al. (Ref 13) suggested that the tensile anisotropy of the A357 alloy stems from crystallographic-dependent strains due to the oversaturation of $\mathrm{Si}$ in the Al matrix. The additional source of anisotropy detected from the crystallographic texture is due to the directional solidification which is a typical outcome of the process.

The diversity of results reported above shows that the orientation dependency of mechanical properties of AM products is not yet fully understood. Additionally, studies about anisotropy of AM produced alloys mainly concern tensile or fatigue performances, whereas little attention is drawn to high-strain rate properties (Ref 18-21). Hadadzadeh et al. (Ref 18) used a split Hopkinson pressure bar apparatus to investigate the compressive impact behavior of differently oriented AlSi10Mg specimens. Despite microstructural features like grains, Al dendrites, Si precipitates, and dislocations density differing as the building orientation changed, the resulting highstrain rate compressive flow behavior was almost identical. Conversely, Rosenthal et al. (Ref 19) found that horizontal samples show a superior high-strain rate tensile behavior compared to vertical samples. They attributed this finding to the different interactions of melt pool boundaries with the fracture path.

So far, the information about the anisotropic high-strain rate behavior of L-PBF processed $\mathrm{Al}$ alloys is inconclusive. Especially as most of the research work has dealt with the alloy in the as-built state. However, different heat treatments can affect the impact behavior of the AlSi10Mg alloy, as previously investigated by the authors (Ref 22). The annealing treatment has resulted in remarkable impact properties, while the microstructural evolution during $\mathrm{T} 6$ treatment has been less beneficial. The deleterious coarsening of porosities during solution treatment could be avoided using high-pressure T6 heat treatment or hot isostatic pressing (HIP) before conventional T6 treatment. However, the effect of heat treatment on the anisotropy of impact properties has not been investigated. Therefore, this research paper aims to investigate the anisotropic Charpy impact behavior of an L-PBF produced AlSi10Mg alloy in different heat treatment conditions. Three different specimen orientations and several heat treatment routes were employed, and the relationship between microstructural features and anisotropic high-strain rate response was investigated. More specifically, this work provides new insights about the inherent anisotropy of AM processed Al alloys and enables a further increase in the comprehension of the role of heat treatment on the impact properties.

\section{Experimental}

\subsection{L-PBF and Heat Treatment}

Impact specimens, with a starting dimension of $12 \times 12 \times 57$ $\mathrm{mm}^{3}$, were manufactured in both horizontal and vertical orientations with respect to the building platform using the LPBF technology by an EOS M290 system. Commercial EOS AlSi10Mg alloy powder with particle size in the range of 25-70 $\mu \mathrm{m}$ (Ref 23) was used. The powder bed with layer thickness of $30 \mu \mathrm{m}$ was selectively melted using laser power of $370 \mathrm{~W}$ and scanning speed of $1300 \mathrm{~mm} / \mathrm{s}$. The manufacturing process was carried out under Argon atmosphere and the platform was preheated at $80{ }^{\circ} \mathrm{C}$. The content of the main alloying elements is reported in Table 1 as measured by optical emission spectrometry (OES).

Specimens were subjected to different heat treatment routes, while some specimens were maintained in the as-built condition for comparison. Figure 1 (a) depicts a scheme of heat treatment conditions with corresponding designation and parameters. In particular, the heat treatments are listed as follows:

- Annealing, performed at $300{ }^{\circ} \mathrm{C}$ for $2 \mathrm{~h}$ with a heating rate of $15^{\circ} \mathrm{C} / \mathrm{min}$, and cooling in air;

- T6, consisting of a solution treatment at $520{ }^{\circ} \mathrm{C}$ for $2 \mathrm{~h}$ (heating rate $15{ }^{\circ} \mathrm{C} / \mathrm{min}$ ) followed by quenching (quench rate $8{ }^{\circ} \mathrm{C} / \mathrm{s}$ ), aging treatment at $180{ }^{\circ} \mathrm{C}$ for $4 \mathrm{~h}$ (heating rate $9{ }^{\circ} \mathrm{C} / \mathrm{min}$ ) and cooling in air;

- HIP (Hot Isostatic Pressing), carried out at $520^{\circ} \mathrm{C}$ for $2 \mathrm{~h}$ (heating rate $15^{\circ} \mathrm{C} / \mathrm{min}$ ) with a pressure of $50 \mathrm{MPa}$ and $150 \mathrm{MPa}$ in a Quintus Technologies HIP machine. The quench rate was approximately $8.3^{\circ} \mathrm{C} / \mathrm{s}$;

- HPT6 (High-Pressure T6), consisting of a HIP treatment followed by aging treatment, both performed at a pressure of $50 \mathrm{MPa}$ and $150 \mathrm{MPa}$. This treatment was carried out in the very same HIP vessel equipped with a rapid quenching unit. In fact, after the HIP treatment, the samples were quenched inside the HIP vessel and subsequently heated up to the aging temperature while maintaining high pressure. Heating and quench rates are comparable with those of the conventional T6 treatment described above. More details on the system for the highpressure heat treatment can be found in (Ref 24);

- HIP+T6, consisting of a HIP treatment followed by conventional T6 treatment. In this case, after HIP, samples were removed from the HIP vessel and T6 treated in a laboratory oven under atmospheric pressure. The parameters of HIP and T6 treatment are the same as reported above.

The samples heat treated at high temperature (i.e. T6, HIP, HPT6 and HIP+T6) are indicated as HTHT (Heat Treatment at High Temperature) samples when necessary, for brevity sake.

After heat treatments, specimens were machined to the final U-notched Charpy specimen dimension $\left(10 \times 10 \times 55 \mathrm{~mm}^{3}\right)$ according to the ASTM E23 standard, as depicted in Fig. 1 (b). In the following, horizontal samples are referred to as XY and YZ depending on whether the U-notch was machined on either the lateral or the top surface of the long side, vertical samples are referred to as XZ (Fig. 1b). Additionally, specimens in Fig. 1(b) will be described simply as having different orientations; however, the actual meaning is that they have a

Table 1 Content of main alloying elements (wt. \%) for the studied alloy

\begin{tabular}{lccc}
\hline $\mathbf{S i}$ & $\mathbf{M g}$ & $\mathbf{F e}$ & $\mathbf{A l}$ \\
\hline 10.2 & 0.39 & 0.21 & Balance \\
\hline
\end{tabular}



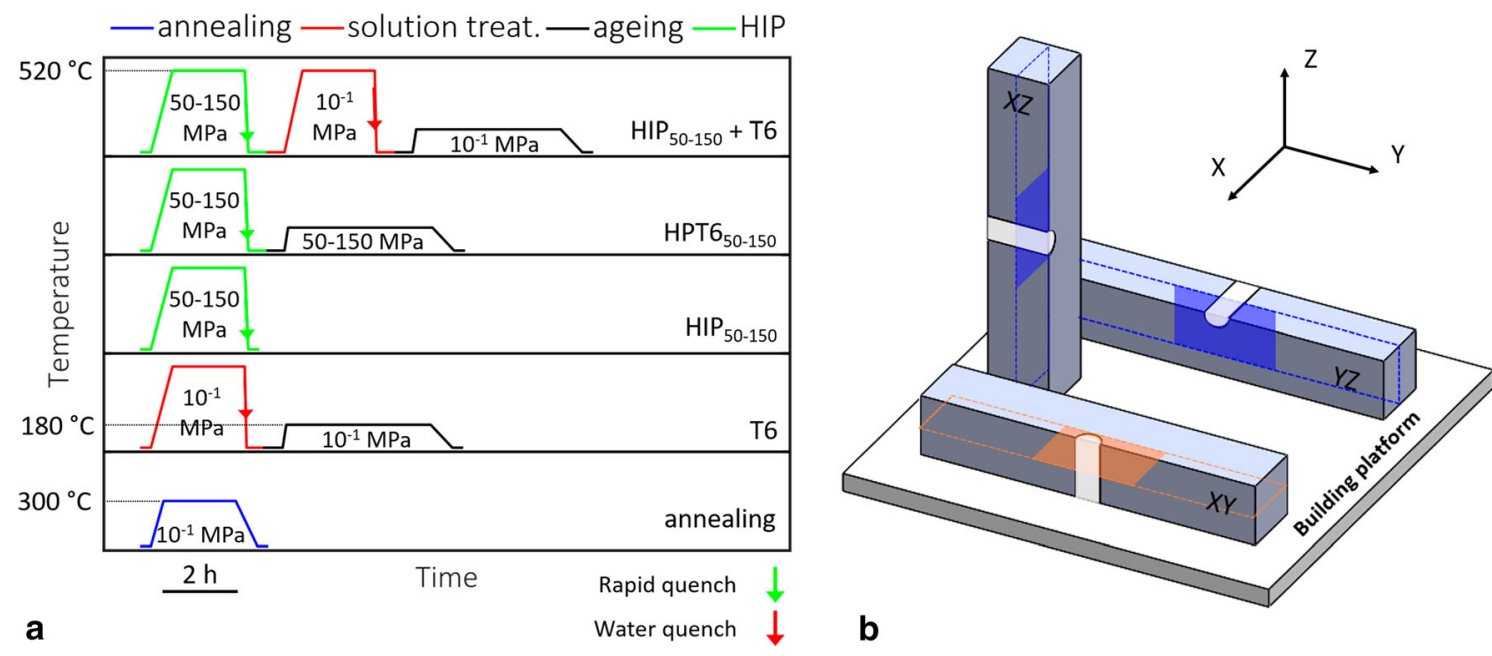

Fig. 1 (a) Schematic of heat treatment conditions. (b) Specimen orientation and corresponding U-notch position

different microstructural arrangement with respect to the fracture direction provided by the U-notch.

\subsection{Charpy Impact Tests}

A CEAST Resil Impactor instrumented pendulum with $50 \mathrm{~J}$ available energy was employed to test the Charpy impact specimens to investigate their high-strain rate behavior. The strain rate during Charpy impact test is estimated between $\sim 10^{2}-10^{3} \mathrm{~s}^{-1}$ (Ref 25,26$)$. It has to be specified that the strain rate is difficult to identify more precisely since it is material dependent and changes with distance from the notch (Ref 25, 26).

At least two specimens for each condition were tested at room temperature $\left(25{ }^{\circ} \mathrm{C}\right)$. Force-displacement data were recorded using a CEAST DAS 64K acquisition system, and further analyzed using a tailored Matlab ${ }^{\circledR}$ code to remove noise and calculate the characteristic impact parameters according to the ISO 14556:2015 standard: peak force $\left(F_{\mathrm{P}},[\mathrm{kN}]\right)$, the maximum recorded force value; initiation energy $\left(E_{\mathrm{i}},[\mathrm{J}]\right)$, the area below the force-displacement curve up to the peak force; propagation energy $\left(E_{\mathrm{P}},[\mathrm{J}]\right)$, the area below the force-displacement curve beyond the peak force. Further details about the analysis of force-displacement curves can be found in other studies (Ref 21).

\subsection{Microstructural Characterization}

Samples for microstructural observations were cut perpendicularly to the U-notch of fractured Charpy specimens. According to Fig. 1 (b), sections parallel (blue) and perpendicular (orange) to the building direction were, respectively, analyzed for $\mathrm{YZ}$ and $\mathrm{XZ}$ samples, and for XY samples. These sections were subjected to standard metallographic preparation and then etched for $10 \mathrm{~s}$ with a $0.5 \mathrm{wt} . \% \mathrm{HF}$ aqueous solution. Metallographic samples and fracture surfaces of Charpy specimens were characterized with a Zeiss EVO MA 15 scanning electron microscope (SEM). Secondary Electron (SE) imaging was used for standard observations, Si phase and fracture surfaces, whereas the crystallographic contrast of Back-Scattered Electrons (BSE) was used for the analysis of grains, owing to their different orientation to the incident beam.
Notably, the following parameters were employed to achieve the desirable crystallographic contrast: accelerating voltage-12 $\mathrm{kV}$, working distance-5 mm, probe current-200 pA. Quantitative image analysis of grains, Si phase and fracture surfaces was performed using the software ImageJ (Ref 27). Grains were analyzed in terms of length and width. Cellular-like Si was analyzed in terms of spacing, measured as the width of the cell. Particle-like Si was analyzed in terms of size and spacing, measured as both equivalent diameter and 3-nearest neighbor $(3 \mathrm{NN})$ distance. Dimples spacing on the fracture surface was measured using the $3 \mathrm{NN}$ distance.

X-ray diffraction (XRD) tests on metallographic sections highlighted in Fig. 1 (b) were conducted using the BraggBrentano geometry on a Bruker D8 Advance diffractometer equipped with a $\mathrm{Cu}$ filament $(\mathrm{K} \alpha, 1.5406 \AA)$. All patterns were acquired in the $2 \theta$ range of $20^{\circ}$ to $110^{\circ}$ with $0.02^{\circ}$ of step-size and $1 \mathrm{~s}$ of step time. Quantitative texture analysis of the $\mathrm{Al}$ phase was performed according to the Harris method (Ref 28, 29). The texture coefficient of the $h k l$ reflection $C_{\mathrm{hkl}}$ and the degree of preferred orientation $\sigma$ were measured according to:

$C_{\mathrm{hkl}}=\frac{I_{\mathrm{hkl}} / I_{\mathrm{hkl}, 0}}{\frac{1}{N} \sum^{N} I_{\mathrm{hkl}} / I_{\mathrm{hkl}, 0}}$

$\sigma=\sqrt{\frac{\sum^{N}\left(C_{h k l}-1\right)^{2}}{N}}$

where $I_{\mathrm{hkl}}$ is the integrated intensity of the $h k l$ reflection in the experimental pattern, $I_{\mathrm{hkl}, O}$ is the integrated intensity of the $h \mathrm{kl}$ reflection of a completely random (texture-free) specimen, and $N$ is the number of the considered reflections. Given the employed $2 \theta$ range reported above, $N=6$ for the $\mathrm{Al}$ phase in the present analysis. The 00-004-0787 file from the International Centre for Diffraction Data (ICDD) was used as the reference random $\mathrm{Al}$ sample. Experimental XRD patterns were fitted using the Rietveld refinement procedure with the software Maud (Ref 30) to isolate the contribution of the Al phase. The integrated intensity of peaks, texture coefficients and degree of preferred orientation were measured using Matlab®. 


\section{Results and Analyses}

\subsection{Microstructural Heterogeneities and Heat Treatment}

Figure 2 depicts the relevant microstructural features of samples in different heat treatment conditions. Cross-sections parallel to the building direction of $\mathrm{YZ}$ samples are chosen as the identified microstructural features are common to all the samples, regardless of the building direction.

In the as-built (Fig. 2a) and annealed (Fig. 2b) samples, dotted lines mark the semi-circular sections of melt pools (Melt Pool Boundaries, MPBs), which host radially elongated grains detected by crystallographic contrast. The $\mathrm{HIP}_{50}$ sample, taken as the reference for all samples heat-treated at high temperatures (for short, HTHT samples in the following), is shown in Fig. 2(c, f, g). This is sufficient to highlight all the microstructural features relevant to the aim of this paper, and a deeper microstructural investigation of HTHT conditions can be found in (Ref 22). MPBs are not discernible after a high-temperature heat-treatment, but their location is suggested by black markers in Fig. 2(c) thanks to the radial growth of elongated grains.

Fine Al cells and Si network (zone 1 or fine zone) compose the inner part of the melt pool in the as-built sample (Fig. 2d). They are coarser in the inner region of the MPB (zone 2 or coarse zone) as compared to zone 1, and the Si network breaks into particles in the outer region (zone 3 or HAZ). After annealing, the $\mathrm{Si}$ network breaks up to form nanometric $\mathrm{Si}$ particles (Fig. 2e) with a coarse size along the MPBs (zone 2) and fine elsewhere (zone 1). In both as-built and annealed samples, the MPB is a few $\mu \mathrm{m}$ thick. Figure 2(f, g) show that both regions within the molten pool and at the MPB of the
$\mathrm{HIP}_{50}$ sample exhibit micrometric Si particles embedded in the Al matrix, with no appreciable differences among them.

Although Fig. 2(c, f, g) refer to the $\mathrm{HIP}_{50}$ sample, they are also representative of the other HTHT samples as they share similar microstructural features. A previous work by the authors (Ref 22) showed that the total exposure at high temperature is the main factor affecting the microstructure at micrometric scale. Conversely, both increased pressure (50-150 $\mathrm{MPa}$ ) and aging treatment have a negligible effect. For instance, HIP $_{50-150}$, HPT6 $6_{50-150}$ and T6 samples exhibit Si particles 1.1$1.2 \mu \mathrm{m}$ in size homogeneously distributed in the Al matrix. The same rules for $\mathrm{HIP}_{50-150}+\mathrm{T} 6$ samples, which exhibit slightly coarser Si particles $(1.4-1.56 \mu \mathrm{m})$ due to a more prolonged exposure at high temperatures.

\subsection{XRD Analyses}

Figure 3 shows the XRD patterns of samples in different orientations and heat treatment conditions. According to Fig. 1 (b), patterns from sections parallel ( $\mathrm{XZ}$ and $\mathrm{YZ}$ samples) and perpendicular (XY samples) to the building direction are depicted in blue and green, respectively. Since HTHT samples share similar XRD patterns (Ref 22), for simplicity only the one corresponding to the $\mathrm{HIP}_{50}$ sample is depicted in Fig. 3.

All patterns show reflections of only $\mathrm{Al}$ and $\mathrm{Si}$ phases, and the intensity of this latter strongly changes with the heat treatment, which is barely distinguishable from the background in as-built samples. Accordingly, a reduced volumetric fraction of 0.094 is calculated by the Rietveld refinement for the $\mathrm{Si}$ phase, which elucidates that a significant amount of $\mathrm{Si}$ is retained in supersaturated solid solution in the Al matrix (Ref 31, 32). The $\mathrm{Si}$ volumetric fraction rises to 0.114 after annealing, and is, on average, 0.117 for HTHT samples, with
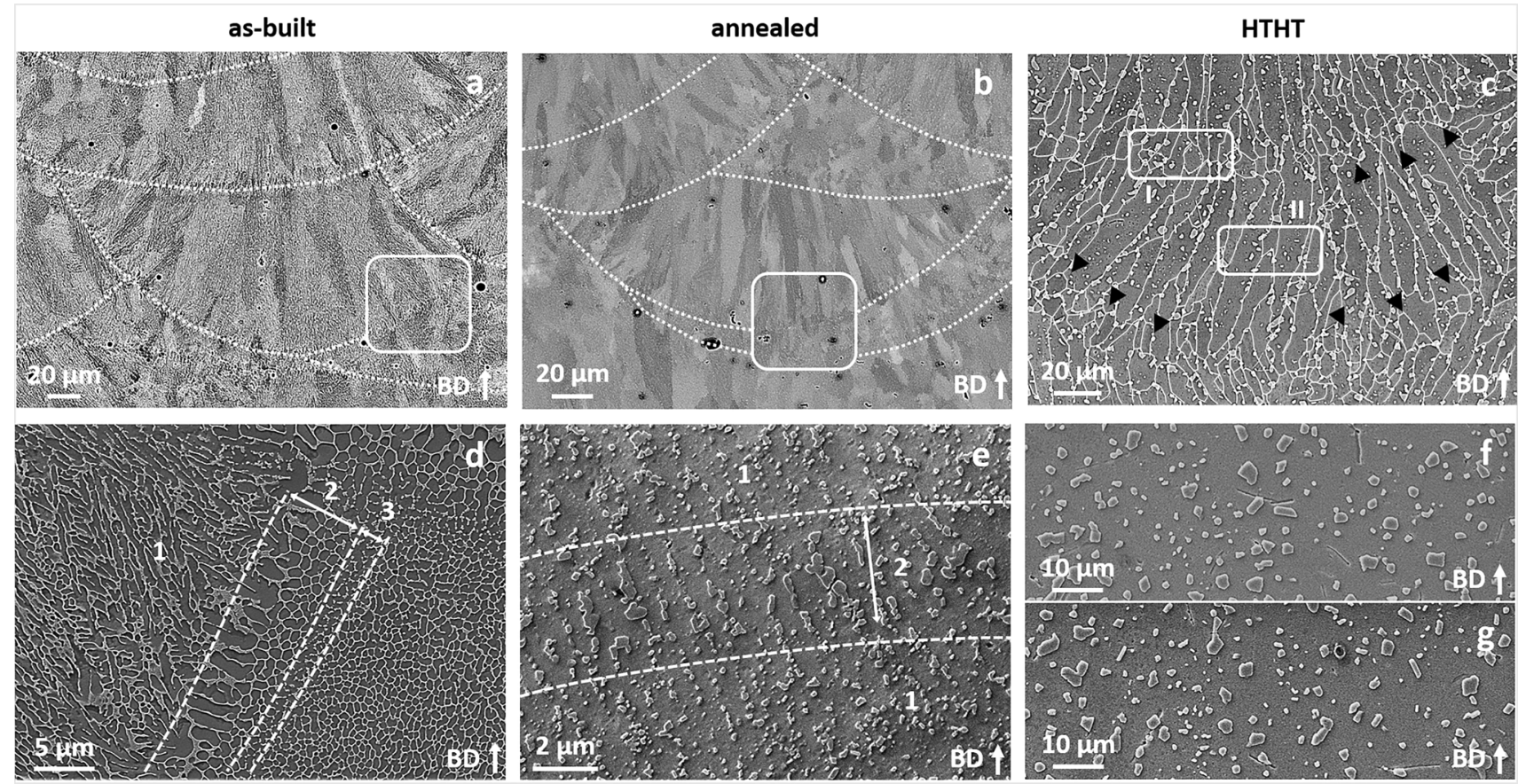

Fig. 2 BSE (a,b,c) and SE (d,e,f,g) images showing the microstructural features in the transverse section of samples in different heat treatment conditions. (a-d) as-built. (b, e) annealed. (c,f,g) HTHT. (a,b) Semi-circular melt pools, dotted lines mark the MPBs. (c) Elongated grains, with boundaries marked by fine solid lines; black markers suggest the location of MPBs. (d,e,f,g) Detailed images taken from areas marked by the solid line in (a,b,c), respectively; showing heterogeneous microstructure at the MPB. In (d,e) dotted lines divide 1-fine zone, 2-coarse zone and 3-HAZ. In all images, the white vertical arrow shows the building direction (BD). 


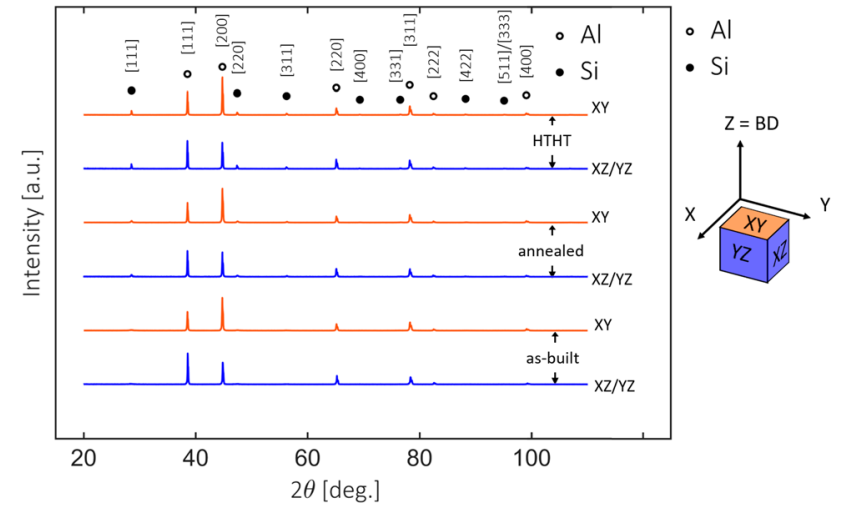

Fig. 3. XRD patterns of specimens in different orientations and heat treatment conditions

0.117 being the equilibrium value of the binary Al-Si system. Therefore, the reduced absolute intensity of $\mathrm{Si}$ reflection in annealed samples as compared to HTHT samples is determined by the nanometric size of Si particles (Fig. 2e).

Additionally, Fig. 3 highlights that the relative intensity of Al peaks changes according to the specimen orientation. For instance, intensities of $[200]_{\mathrm{Al}}$ and $[111]_{\mathrm{Al}}$ reflections are similar for the $\mathrm{YZ}$ and $\mathrm{XZ}$ specimens, whereas the former is significantly higher for the $\mathrm{XY}$ specimens. In a texture-free sample, the $[111]_{\mathrm{Al}}$ reflection should be the most intense, suggesting that a crystallographic texture exists in both parallel and perpendicular sections to the building direction (Ref 33, $34)$.

\subsection{Orientation-Dependent Impact Properties}

The analysis of the impact test results was conducted through the evaluation of the characteristics parameters, i.e., the maximum recorded force value named $\mathrm{F}_{\mathrm{P}}$, the area below the force-displacement curve up to the peak force named $E_{i}$ and the area below the force-displacement curve beyond the peak force named $E_{\mathrm{P}}$. Figure 4 shows the Charpy impact parameters calculated from force-displacement curves as a function of heat treatment and specimen orientation.

The as-built samples have a high impact strength, as compared to the other investigated conditions, with a peak force $F_{\mathrm{p}}$ of $\sim 6.8-6.9 \mathrm{kN}$ independently of the specimen orientation (Fig. 4a). Conversely, absorbed energies suffer from significant anisotropy. Both initiation energy $E_{\mathrm{i}}$ (Fig. 4b) and propagation energy $E_{\mathrm{p}}$ (Fig. $4 \mathrm{c}$ ) progressively decrease for XY, $\mathrm{YZ}$ and $\mathrm{XZ}$ samples in this order.

After annealing, the alloy retains an impact strength comparable to the as-built state, with $\mathrm{F}_{\mathrm{p}}$ ranging between 6.6 and $7.1 \mathrm{kN}$. Besides, $\mathrm{E}_{\mathrm{i}}$ and $\mathrm{E}_{\mathrm{p}}$ increase by about threefold and fivefold the corresponding values of the as-built samples up to 6-10 J to 8-12 J, respectively. However, the anisotropic impact response is not mitigated after heat treatment: all impact parameters reach the highest and lowest values for the XY and $\mathrm{XZ}$ samples, respectively, with YZ samples located in-between them.

After the HIP treatment, either at 50 or $150 \mathrm{MPa}, \mathrm{F}_{\mathrm{p}}$ reduces to 5.3-5.8 kN, while $\mathrm{E}_{\mathrm{i}}$ and $\mathrm{E}_{\mathrm{p}}$ each reach about $6 \mathrm{~J}$ and $5 \mathrm{~J}$. All specimen orientations show similar absorbed energies, considering the experimental uncertainty, whereas $F_{p}$ is slightly higher for XZ samples. After microstructure homogenization, either with solution treatment or both HIP and solution treatment, the aging treatment strengthens the alloy, with $\mathrm{F}_{\mathrm{p}}$ of T6, HPT6, and HIP + T6 samples ranging between 6.5 and $7.5 \mathrm{kN}$. As a drawback, $E_{i}$ and $E_{p}$ fall to 3-4 $\mathrm{J}$ and 0.5-2 J, respectively. These values are significantly lower than those for samples under as-built and annealed conditions.

To summarize, Figure 4 shows no significant differences in absorbed energies and impact strength of samples mentioned above (i.e. HIP, HPT6, T6 and HIP+T6) as the specimen orientation changes, although strength anisotropy cannot be completely ruled out due to the high scattering of experimental data.

\subsection{Micro-Scale Damaging Mechanism and Fracture Behavior}

Charpy specimens were cut and polished to the midthickness plane to analyze the microstructure just beneath the fracture profile, and the primary micro-scale damage mechanism was investigated. Figure $5(\mathrm{a}, \mathrm{b})$ depict the damage features of the as-built alloy at different magnifications. Irregular voids grow at the $\mathrm{Al} / \mathrm{Si}$ interface, primarily due to the decohesion of adjacent phases and occasionally through the rupture of the Si network. Generally, a reduced number of voids with a relatively coarse size is detected for the as-built alloy.

In the annealed samples (Fig. 5c, d), voids with a regular morphology nucleate by decohesion of Si particles from the Al matrix. Damage by breakage of Si particles was not detected but, in light of the nanometric size of Si particles, it cannot be ruled out undoubtedly. As compared to as-built samples, the damage is significantly diffused in annealed samples, with a higher number of smaller sized voids at fracture. Damage also nucleates at coarse Si particles in HTHT samples (Fig. 5e, f), either by decohesion from the parent matrix or breakage of $\mathrm{Si}$ particles. Figure 5(f) shows that the growth and coalescence of adjacent voids is a likely damaging mechanism.

The Si phase mainly rules the damage nucleation at the micro-scale, but its microstructural heterogeneity ( $\S 3.1$ ) requires investigating the fracture behavior at a broader scale.

Fracture profiles of samples in different orientations and heat treatment conditions are depicted in Fig. 6. Longitudinal/ elongated and transverse/semi-circular sections of melt pools are detected for XY (Fig. 6a, b), and for YZ and XZ samples (Fig. 6d, e, g, h), respectively, due to the different size and morphology of the Si phase along the MPBs, marked with dotted lines in Fig. 6. Melt pools are not discernible in HTHT samples (Figs. 6c, f, i), even if MPBs are suggested by the radial arrangement of elongated grains in $\mathrm{YZ}$ and $\mathrm{XZ}$ samples. In HTHT samples, grain boundaries are marked by the superimposition of fine solid lines.

In as-built (Fig. 6a) and annealed (Fig. 6b) XY samples, the fracture profile crosses the melt pools transversally, with only limited zones following the MPBs. The presence of sole equiaxed grains prevents a detailed interpretation of the fracture path in HTHT XY samples (Fig. 6c). The fracture profile still significantly crosses the melt pools in as-built (Fig. 6d) and annealed (Fig. 6e) YZ specimens, but often deviates from its straight path to follow the MPBs. MPBs mainly compose fracture profiles of XZ samples in as-built (Fig. 6g) and annealed (Fig. 6h) states. Secondary cracks along the MPBs beneath the fracture profile (Fig. 6g) indicate that they are a favorable fracture path. In HTHT YZ (Fig. 6f) and XZ (Fig. 6i) samples, the arrangement of elongated grains suggests that the 


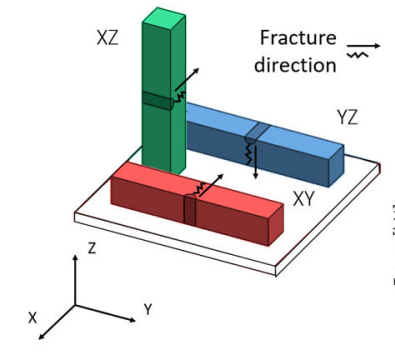

a

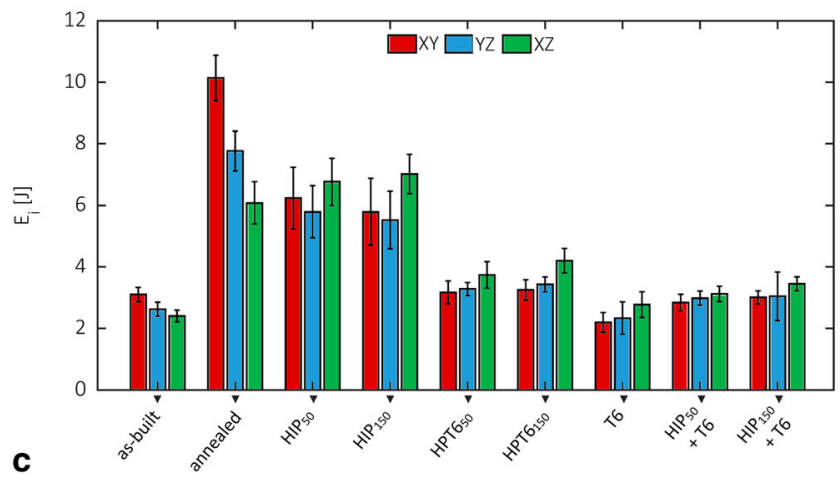

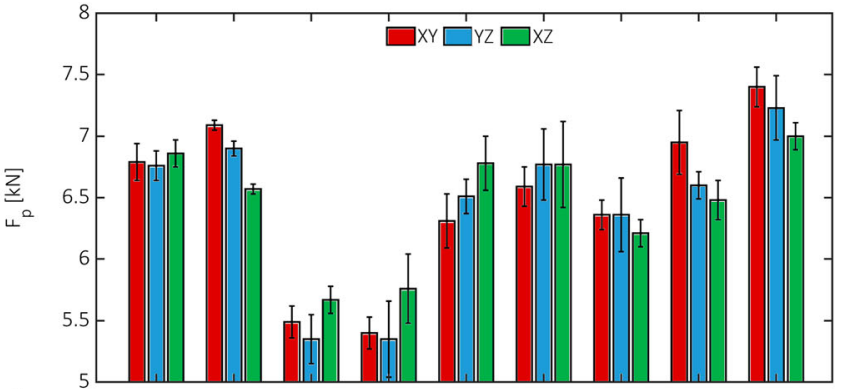

b

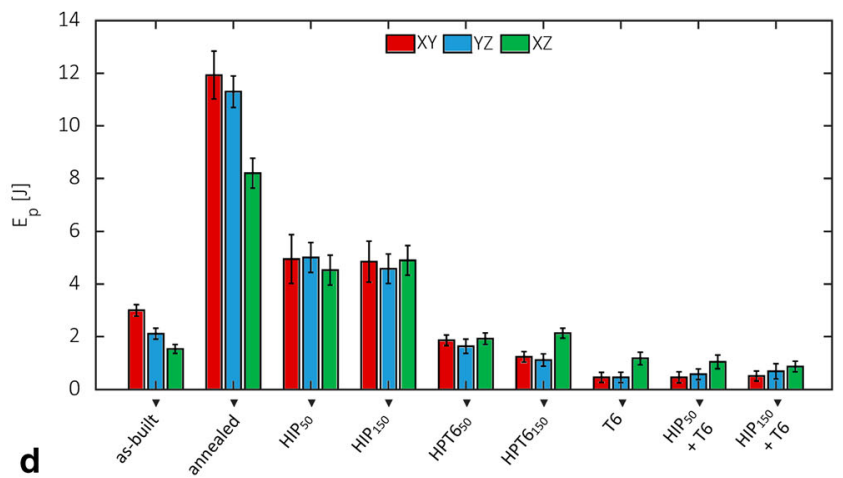

Fig. 4 Impact parameters from Charpy force-displacement curves of specimens in different heat treatment conditions and orientations. (a) Schematic of Charpy specimens, representative force-displacement curve and corresponding impact parameters. (b) Peak force. (c) Initiation energy. (d) Propagation energy. Standard deviations are shown as error bars
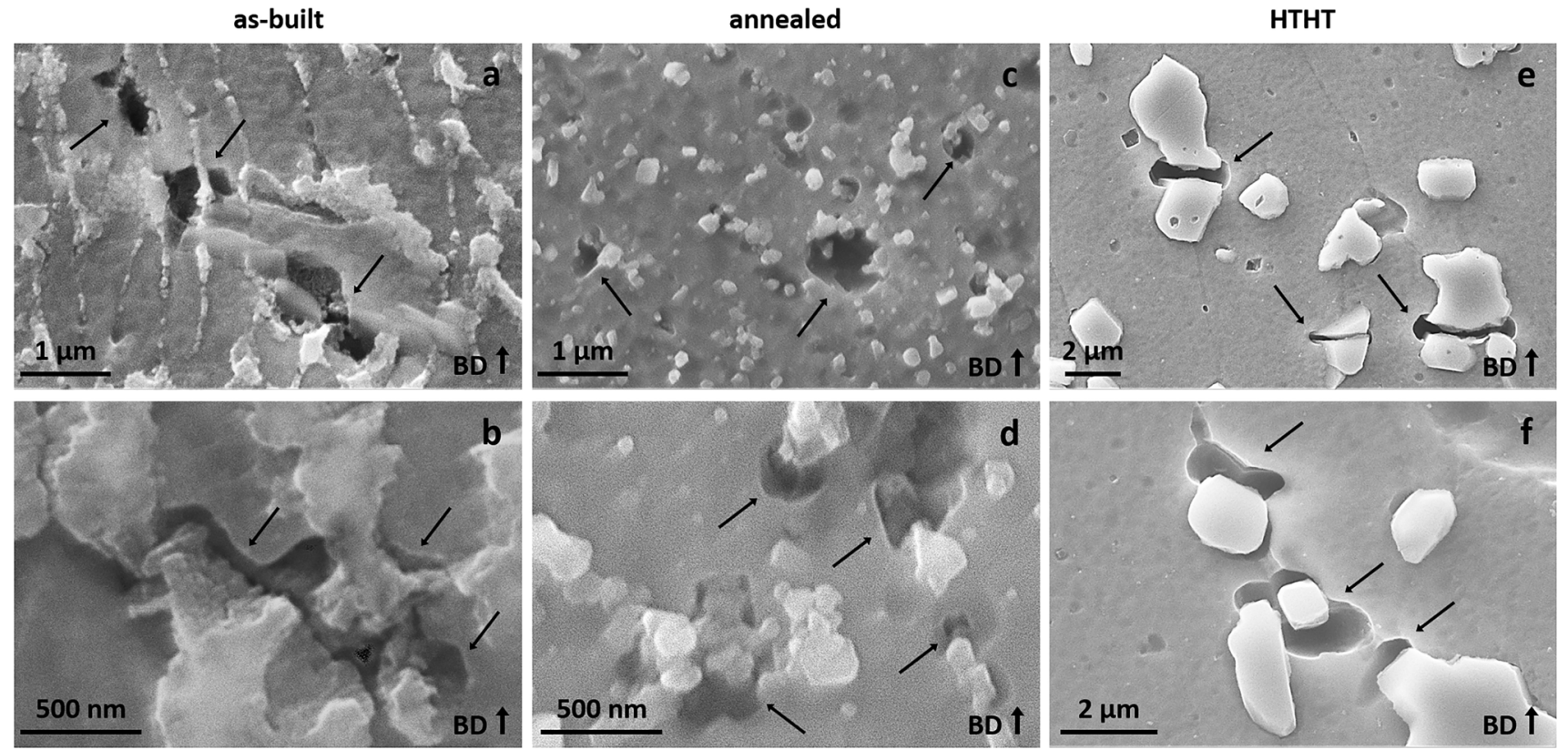

Fig. 5 SE images showing the fracture mechanism of specimens in different heat treatment conditions. (a, b) as-built. (c, d) annealed. (e, f) HTHT. Fine arrows mark the nucleation of voids at the Si phase. Vertical arrows in the bottom-right corner mark the building direction (BD)

fracture path is coherent with both the observations in Fig. 6 (d, $\mathrm{e}, \mathrm{g}, \mathrm{h})$.

Figure 7 depicts the fracture surfaces of samples shown in Fig. 6 to complement the observation of fracture profiles. Semicircular sections of melt pools are detectable on the fracture surface of the as-built XY sample (Fig. 7a), whereas they are seldom recognizable in the annealed XY sample (Fig. 7b). An irregular dimple-like surface characterizes the HTHT XY samples (Fig. 7c), and no features recall the shape of melt pools. In the as-built YZ sample (Fig. 7d), semi-circular traces of melt pools are easily recognizable. A more in-depth analysis reveals fine elongated dimples in the inner part of the melt pools (Fig. 7d') and coarse elongated dimples along the trace of the MPB (Fig. 7d"), matching the microstructural hetero- 

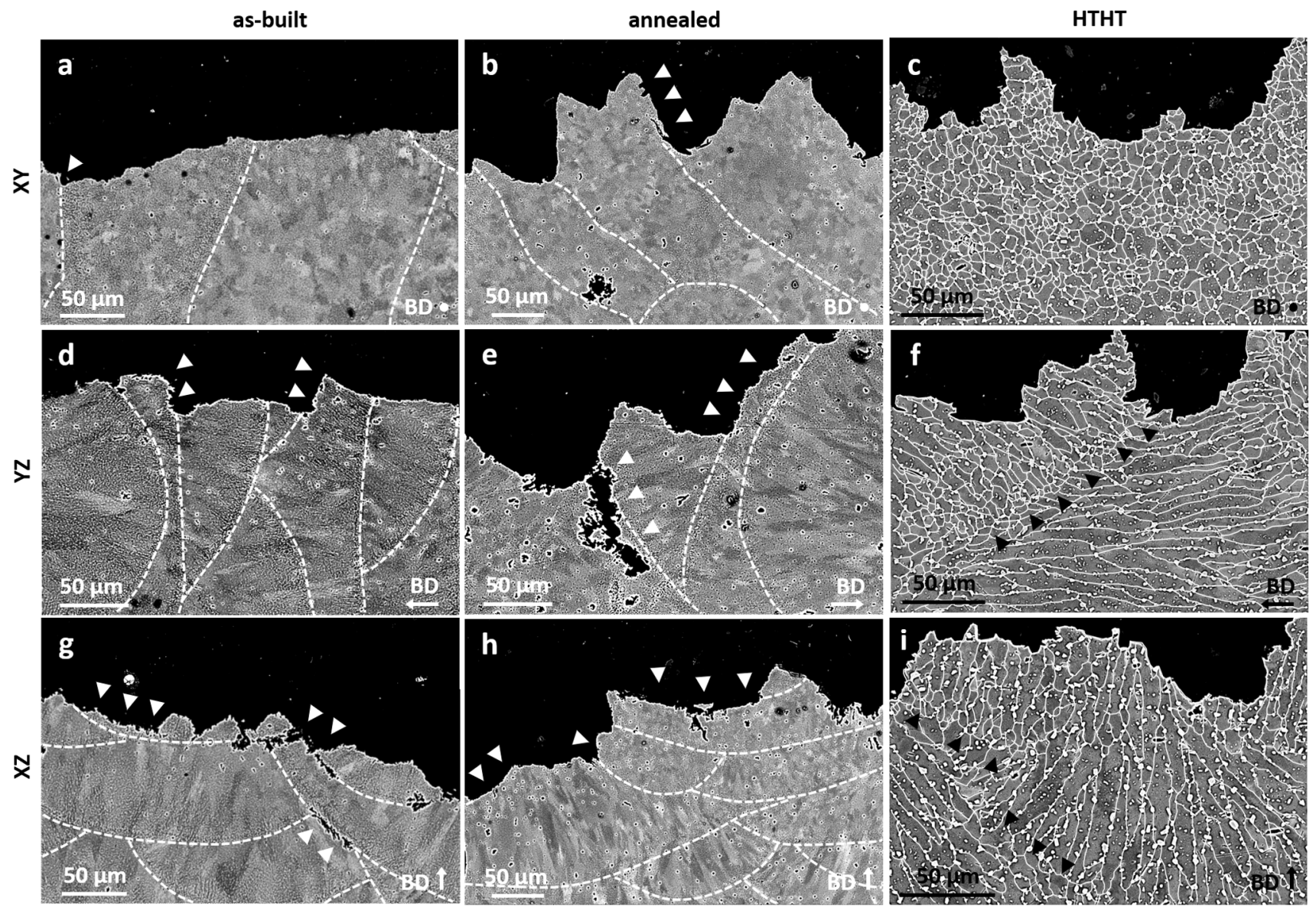

Fracture direction

Fig. 6 BSE images showing the fracture profiles of specimens in different orientations and heat treatment conditions. (a, b, c) XZ. (d,e, f) XY. (g, h, i) Z. (a, d, g) as-built. (b, e, h) annealed. (c, f, i) HTHT. In the as-built and annealed samples, dashed lines mark the MPBs, and white markers indicate a fracture along MPBs. In the HTHT specimens, the black markers suggest the MPBs, solid white lines mark the grain boundaries. Arrows and dots in the bottom-right corner mark the building direction (BD)

geneities of the Si phase (Fig. 2d) and supporting its role in damage nucleation (Figs. 5a,b).

Traces of melt pools are still detectable on the fracture surface of the annealed YZ sample (Fig. 7e), where equiaxed dimples are small inside the melt pool (Fig. 7e') and coarse along the MPB (Fig. 7e"), in agreement with Fig. 2(e). Conversely, the coarse dimple-like appearance of the fracture surface of HTHT YZ samples (Fig. 7f) is consistent in size and morphology, as highlighted by the similarity of Fig. 7(f') and (f'). Fracture surfaces of as-built (Fig. 7g) and annealed (Fig. 7h) XZ samples clearly show elongated scan tracks (Ref 21), which are no longer detectable in HTHT XZ samples (Fig. 7i).

\section{Discussion}

\subsection{Anisotropic Impact Behavior with Heat Treatments}

Figure 4 shows that the high-strain rate behavior of the alloy is strongly affected by heat treatment. As-built samples show a remarkable impact strength, which stems from the hierarchical ultra-fine microstructure (Fig. 2d) and the supersaturated solid solution of Si in the Al phase (Fig. 3). Besides, residual process defects, like residual stresses (Ref 35) and high dislocation density (Ref 36), limit the absorbed energy to values $<5 \mathrm{~J}$. Breakage of Si network into nanometric particles (Fig. 2e) and reduced solid solution (Fig. 3) improve the ductility of annealed samples, increasing the absorbed energy to 14-22 J. Meanwhile, the same impact strength of as-built samples is retained. As compared to the highly strengthened as-built alloy, the microstructure of the annealed material is more easily deformed, promoting formation and movement of several new dislocations and a higher strain rate sensitivity (Ref 22). As a consequence, the strength of the annealed material in impact tests increases up to that of the as-built material. Coarsening of Si particles (Fig. 2f, g) and absence of precipitation strengthening improve initiation and propagation energies $(\sim 6$ and $\sim 5$ $\mathrm{J}$, respectively) of HIP samples at the expense of strength, which falls to $\sim 5.5-6 \mathrm{kN}$. Precipitation of strengthening compounds restores a high impact strength of $\sim 6.5-7.5 \mathrm{kN}$ but reduces ductility and absorbed energy in T6, HPT6 and HIP + T6 samples, especially in comparison with as-built and annealed conditions. No substantial influence of pressure on impact properties was observed among samples treated at high pressure, as previously reported (Ref 22).

Figure 4 also shows that the orientation-dependent Charpy impact behavior changes with the heat treatment state. Strength and absorbed energy of as-built and annealed samples signif- 

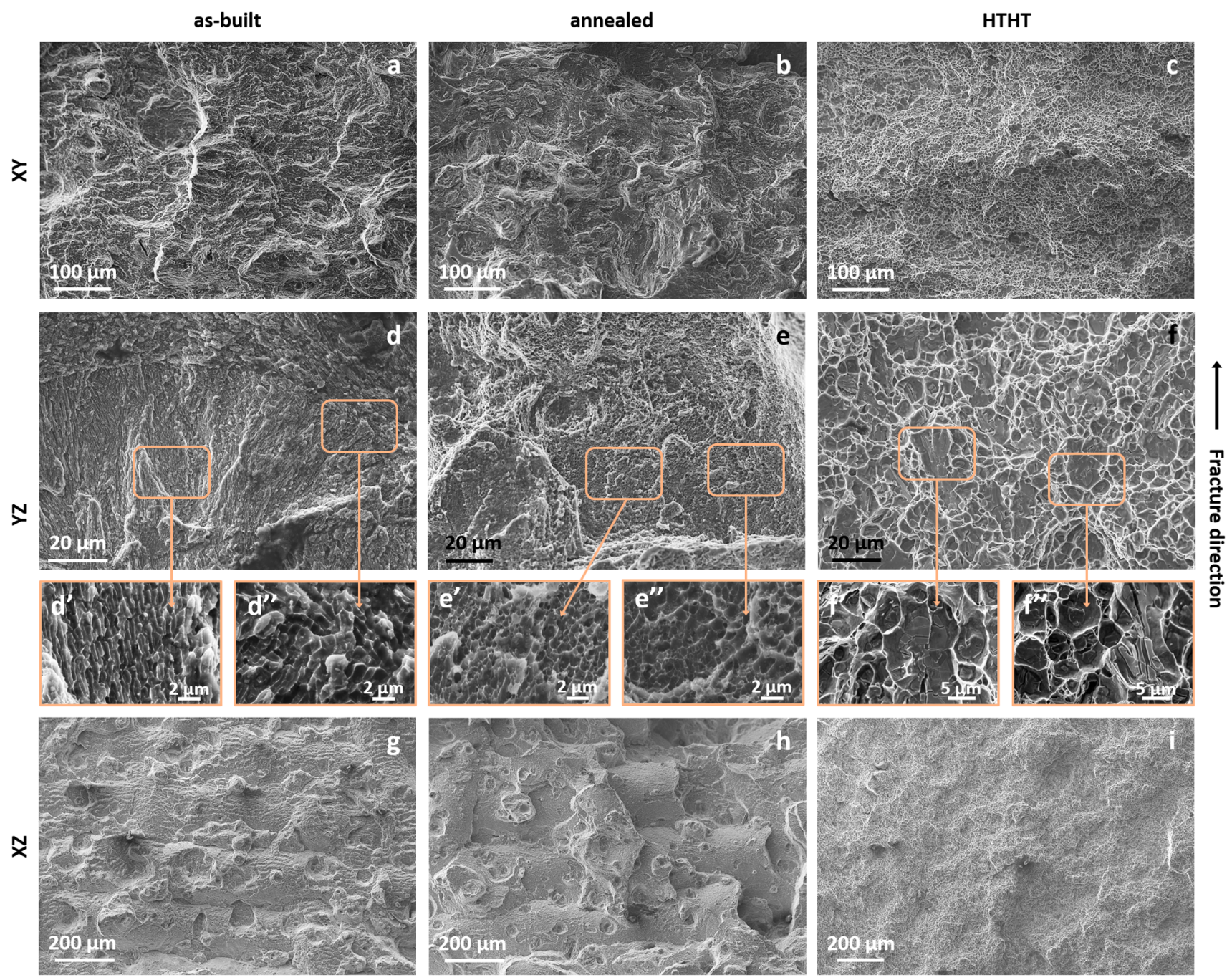

Fig. 7 SE images showing the fracture surfaces of specimens in different orientations and heat treatment conditions. (a-b-c) XZ. (dd'-d"-e-e'-e"f-f'-f") XY. (g-h-i) Z. (a-d-d'-d"-g) as-built. (b-e-e'-e"-h) annealed. (c-f-f'-f"-i) HTHT. (d'-d"), (e'-e"), (f'-f') Detailed images taken from the areas marked by the solid orange line in (d), (e), (f). (d'-e'), (d"-e") Detailed images taken from the core and boundary of the melt pools traces, respectively

icantly depend on specimen orientation, decreasing for $\mathrm{XY}, \mathrm{YZ}$ and $\mathrm{XZ}$ samples in this order, whereas impact properties are more consistent after heat treatment at high temperatures.

\subsection{Role of Morphological and Crystallographic Textures}

Among others, elongated grains morphology possibly induces anisotropic mechanical properties in AM produced alloys (Ref 14, 15). Therefore, Fig. 8 depicts the statistical distributions of grains' width and length as a function of specimen orientation and heat treatment.

Transversally sectioned grains appear equiaxed in YY samples (Fig. 6a, b, c), with width and length being similar. In as-built and annealed samples, the maximum grain size is $\sim 10 \mu \mathrm{m}$, whereas it is slightly higher in HTHT samples, and can go up to $15 \mu \mathrm{m}$. Longitudinally sectioned grains appear with an elongated shape in YZ (Fig. 6d, e, f) and XZ (Fig. 6g, $\mathrm{h}$, i) samples, with their width ranging between 1 and $10 \mu \mathrm{m}$ and their length spanning over several tens of $\mu \mathrm{m}$ in each heat treatment state. Although a slight coarsening is sometimes reported (Ref 37, 38), starting size and elongated shape of grains are almost fully maintained with the heat treatment.
Since this latter significantly levels out the impact properties (Fig. 4), grain morphology is unlikely the main reason for anisotropy. Indeed, Xiao et al. (Ref 33) found that a nano-TiB ${ }_{2}^{-}$ added AlSi10Mg alloy with an equiaxed crystal structure still exhibits anisotropic tensile properties, although anisotropy is reduced when compared to the columnar-grained counterpart. Other studies concerning the anisotropic response of different alloys concluded that grain morphology is, to some extent, an influencing factor (Ref 39, 40). However, the contribution of grain morphology cannot be completely ruled out: their elongated shape yields columnar and equiaxed grains on the load-bearing sections of $\mathrm{YZ} / \mathrm{XY}$ and $\mathrm{XZ}$ specimens, respectively. This contributes to the anisotropy of as-built and annealed samples and likely accounts for small residual differences of impact properties of differently oriented HTHT specimens.

Another reported cause of anisotropy of AM processed alloys is crystallographic texture (Ref $8,10,17)$, which affects the mutual orientation of slip and loading directions (Ref 41) and thus the mechanical response according to Schmid's law (Ref 42). Diffractograms in Fig. 3 suggest that a preferred 
orientation of the Al phase exists in sections both parallel and perpendicular to the building direction. The Harris method was employed to analyze texture from XRD patterns quantitatively, and the results are listed in Table 2.

The integrated intensity of $[111]_{\mathrm{Al}}$ and $[200]_{\mathrm{Al}}$ reflections is similar in $\mathrm{YZ}$ and $\mathrm{XZ}$ samples, while a $\sim 1: 2$ ratio exists in $\mathrm{XY}$ samples, regardless of heat treatment. Texture coefficient is generally $>1$ for $[200]_{\mathrm{Al}},[311]_{\mathrm{Al}},[400]_{\mathrm{Al}}$ reflections and $<1$ for the remaining ones. The calculated degree of preferred orientation $\sigma$ is always $>0$, further supporting the presence of a texture in both sections parallel (YZ/XZ) and perpendicular $(\mathrm{XY})$ to the building direction. Additionally, $\sigma$ is much higher for XY samples, which matches with a possible [100] fiber texture typical of AM produced Al alloys (Ref 43, 44).

$\sigma$ slightly increases with the heat treatment temperature, but the difference between $\mathrm{YZ} / \mathrm{XZ}$ and $\mathrm{XY}$ samples is almost the same for as-built, annealed, and HTHT samples, indicating that the preferred orientation of $\mathrm{Al}$ phase is not recovered during heat treatment. Although pole figures would guarantee a comprehensive evaluation of texture, results of the current simplified method match the analysis of diffractograms previously reported in the literature ( $\operatorname{Ref} 33,34)$. According to the aim of the present work, they satisfactorily show that the reduced anisotropy of impact properties with heat treatment cannot be explained by the removal of the preferred orientation of the Al phase. As stated for the grain morphology, the retainment of crystallographic texture could justify the slight residual dependence on specimen orientation of HTHT samples.

\subsection{Role of Microstructural Heterogeneities}

The gradient evolution of the microstructure of an L-PBF produced AlSi10Mg alloy primarily regards the Si phase in asbuilt (Fig.2d) and annealed samples (Fig. 2e), while HTHT samples exhibit a uniform microstructure (Fig. 2f, g). Similarly, heterogeneous dimples are detected on fracture surfaces of asbuilt (Fig. 7d-d'-d") and annealed (Fig. 7e-e'-e") samples, whereas they are uniformly spaced on fracture surfaces of samples heat-treated at high temperatures (Fig. 7f-f'-f'). As the evaluation of the damage mechanism (Fig. 5) highlights the primary role of the Si phase (Ref 45$)$, a quantitative analysis of size and spacing of microstructural and fractographic features of differently heat-treated samples was performed (Ref 46). YZ samples were selected as the reference owing to the easier detectability of traces of melt pools on their fracture surface. Results are listed in Table 3.

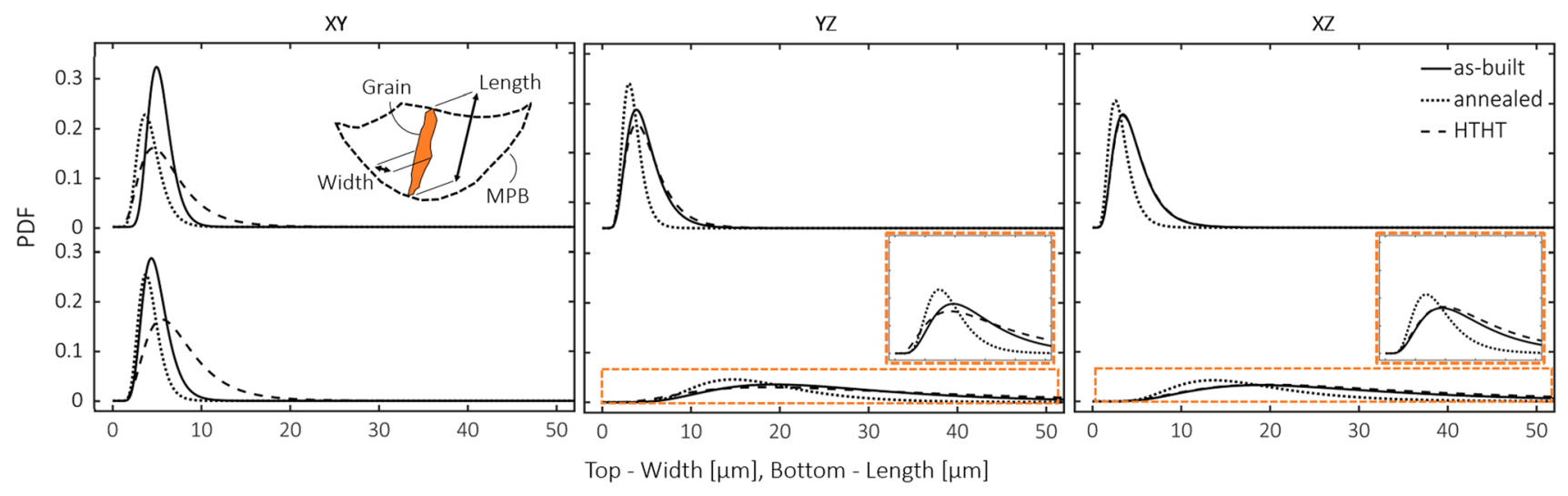

Fig. 8 Statistical distributions of width and length of grains of samples in different orientations and heat treatment conditions

Table 2 Analysis of XRD patterns of specimens in different orientations and heat treatment conditions: normalized intensity to the maximum value $(I \%)$, texture coefficients $\left(C_{\mathrm{hkl}}\right)$ and degree of preferred orientation $(\sigma)$

\begin{tabular}{|c|c|c|c|c|c|c|c|c|}
\hline & & Al reference 00-004-0787 & as-built $\mathrm{XY} / \mathrm{Z}$ & as-built $\mathrm{XZ}$ & Annealed XY/Z & Annealed XZ & HTHT XY/Z & HTHT Z \\
\hline \multirow{6}{*}{ I \% } & {$[111]$} & 100 & 100 & 53.4 & 95.0 & 48.5 & 95.1 & 52.3 \\
\hline & [200] & 47 & 86.8 & 100 & 100 & 100 & 100 & 100 \\
\hline & {$[220]$} & 22 & 39.4 & 24.8 & 45.6 & 21.4 & 44.0 & 22.6 \\
\hline & [311] & 24 & 47.2 & 38.5 & 51.3 & 34.9 & 52.6 & 37.3 \\
\hline & [222] & 7 & 9.4 & 5.0 & 8.9 & 4.5 & 9.5 & 5.2 \\
\hline & {$[400]$} & 2 & 6.7 & 7.7 & 7.7 & 7.6 & 8.4 & 8.4 \\
\hline $\mathrm{C}_{111}$ & & 1 & 0.53 & 0.32 & 0.46 & 0.31 & 0.44 & 0.31 \\
\hline $\mathrm{C}_{200}$ & & 1 & 0.98 & 1.28 & 1.03 & 1.35 & 1.00 & 1.25 \\
\hline $\mathrm{C}_{220}$ & & 1 & 0.95 & 0.68 & 1.00 & 0.62 & 0.94 & 0.61 \\
\hline $\mathrm{C}_{311}$ & & 1 & 1.04 & 0.97 & 1.04 & 0.92 & 1.02 & 0.91 \\
\hline $\mathrm{C}_{222}$ & & 1 & 0.71 & 0.43 & 0.61 & 0.40 & 0.64 & 0.44 \\
\hline $\mathrm{C}_{400}$ & & 1 & 1.78 & 2.32 & 1.86 & 2.40 & 1.96 & 2.48 \\
\hline$\sigma$ & & 0 & 0.39 & 0.67 & 0.44 & 0.72 & 0.48 & 0.73 \\
\hline
\end{tabular}


In the as-built state, the dimples spacing in different areas of the fracture surface (Fig. 7d) matches with the width of $\mathrm{Al}$ cellular dendrites (spacing of Si network) in fine and coarse zones of the melt pool and with the spacing of Si particles in the HAZ. Heterogeneous fractographic features are also detected in the annealed state, and their spacing also matches the spacing of nanometric Si particles in both fine and coarse zones. As traces of melt pools are not discernible on the fracture surface in the HTHT state, a single value of dimple spacing is measured, and it roughly corresponds to the spacing of micrometric $\mathrm{Si}$ particles. The excellent match between microstructural and fractographic features confirms the primary role of Si heterogeneities in damage nucleation and fracture (Fig. 5).

Heterogeneous microstructure means locally different properties, which affect strength and fracture behavior. Several microstructural features contribute to strength in the L-PBF produced AlSi10Mg alloy (Ref 33), but just the Si contribution will be considered here for the sake of comparison and according to its primary role in damage behavior (Fig. 5). The operating strengthening mechanisms of $\mathrm{Si}$, the corresponding constitutive equations, and the resulting strength increment $\Delta \sigma_{\mathrm{y}}$ calculated according to data in Table 3, are reported in Fig. 9 as a function of heat treatment.

In as-built samples, $\mathrm{Si}$ strengthens the alloy by the HallPetch relationship in fine and coarse zones, and by the Orowan relationship in the HAZ, with the resulting $\Delta \sigma_{\mathrm{y}}$ being $\sim 50$, $\sim 40$ and $\sim 7 \mathrm{MPa}$. Only the Orowan mechanism operates in the annealed alloys, and $\Delta \sigma_{\mathrm{y}}$ is $\sim 12$ and $\sim 6 \mathrm{MPa}$ for fine and coarse zones. The micrometric size of $\mathrm{Si}$ particles yields a negligible $\Delta \sigma_{\mathrm{y}}$ in HTHT alloys. It is worth noting that the actual volumetric fraction of Si measured by XRD was used in the Orowan relationship: 0.094 in the as-built samples, owing to the supersaturated solid solution of $\mathrm{Si}$ in the $\mathrm{Al}$ matrix, and 0.114 and 0.117 in annealed and HTHT samples, respectively, (§ 3.2). Simplified calculations show that MPBs represent the weakest part of the microstructure in as-built and annealed samples, whereas the homogeneous microstructure yields uniform properties in HTHT samples.

\subsection{Role of Specimen Orientation}

Since MPBs represent a significant weakness in as-built and annealed samples, their distribution along the deformation and

Table 3 Analysis of microstructural and fractographic features of XY specimens in different heat treatment conditions: size $\left(d_{e q}\right)$ of Si phase, spacing $(\bar{d})$ of Si phase and dimples

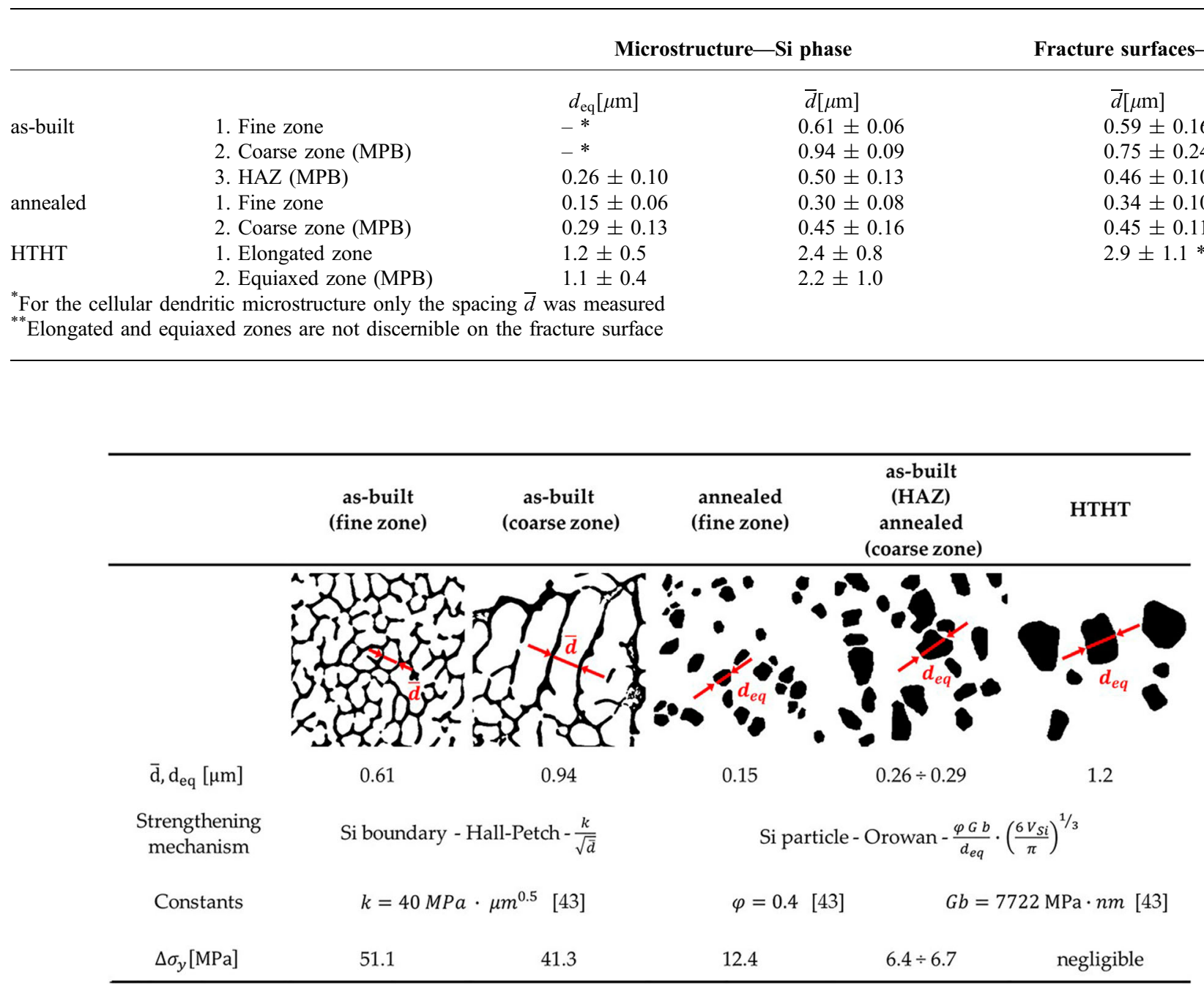

Fig. 9 Strengthening mechanisms of Si phase in different heat treatment conditions. Reference in the picture 
fracture path could affect the material response and possibly cause anisotropic properties. By analyzing several fracture profiles as those depicted in Fig. 6, the length of fracture path occupied by MPBs was estimated as $8-10 \%, 22-25 \%$ and $42-$ $45 \%$ for XY, YZ and XZ samples, respectively, both in as-built and annealed states. Similar measurements were not achieved for HTHT samples, which do not exhibit MPBs. However, the analysis of Fig. 6(c), (f), (i) suggests a fracture path similar to as-built and annealed samples in regard to the specimen orientation changes.

Considering the reduced strength of MPBs and their distribution along the fracture path as the specimen orientation changes, decreasing impact properties are expected for XY, YZ and $\mathrm{XZ}$ samples, in this order, both in as-built and annealed samples. On the contrary, a more uniform high-strain rate behavior is expected in HTHT samples due to homogeneous microstructure. These outcomes match the analysis of impact properties in Fig. 4, elucidating that the mitigation of anisotropic impact behavior of the alloy is related to the recovery of microstructural heterogeneities. This is consistent with recent studies (Ref 47, 48) on the tensile properties of AlSi10Mg alloy under as-built and annealed conditions, where MPBs are clearly indicated as the main responsible for the anisotropic behavior of the alloy under quasi-static loading.

Some differences in impact properties of HTHT samples as the specimen orientation changes may be suggested from Fig. 4. Such residual anisotropy results are likely due to the retainment of elongated grains morphology and crystallographic texture after heat treatment. Further heat treatment routes and treatment parameters will be investigated in future work to mitigate the effect of residual sources of anisotropy. However, the current research activity provides valuable insights about the anisotropic high-strain rate behavior of the L-PBF produced AlSi10Mg alloy and lays the foundation for selecting proper heat treatment parameters to achieve a fully isotropic material.

\section{Conclusion}

The present research activity deals with the anisotropic Charpy impact behavior of an L-PBF produced AlSi10Mg alloy in different heat treatment conditions. Primary possible sources of anisotropy were investigated to assess the relationship between impact parameters and specimen orientation. The following conclusions can be drawn:

- Significant anisotropy affects the impact behavior of the alloy in as-built and annealed conditions. Conversely, exposure to high temperatures generally yields more isotropic mechanical properties, whose absolute values depend on the given heat treatment route.

- Regardless of heat treatment, the Si phase primarily rules damage nucleation during deformation at a high-strain rate. The excellent match between microstructural and fractographic features supports this outcome.

- Anisotropy of as-built and annealed samples depends on microstructural features, such as elongated grain morphology, preferred orientation of the $\mathrm{Al}$ phase and heterogeneous $\mathrm{Si}$ phase. This latter is homogenized after heat treatments at high temperatures, which significantly promotes isotropy.
- A simple analysis shows that MPBs represent the weakest microstructural feature, and their distribution along the fracture path affects isotropy, leading the impact behavior to change with the specimen orientation.

\section{Acknowledgments}

The authors gratefully acknowledge $\mathrm{Mr}$ J. Shipley and $\mathrm{Mr}$ J. Gårdstam (Quintus Technologies AB) for their support with HIP and HPT6 treatments, Dr L. Girelli for the valuable technical support and Mr G. Bertocchi for help in XRD testing.

\section{Author contributions}

MG and MF performed the SEM and XRD characterization and corresponding data analysis. MT performed the heat treatments. AF conducted the Charpy impact tests; MG analyzed the corresponding data. MM acquired funding and supervised the work. AP and MT acquired the additively manufactured specimens and HIP treatments and supervised the work. MG wrote the first draft of the manuscript. All authors contributed to reviewing and editing the manuscript and discussing and interpreting all the results.

\section{Funding}

This work was partially funded by the University Found for the Scientific Research (FAR) 2019, Prot. n. 84130 of the University of Ferrara (Italy).

\section{Data availability}

The data that support the findings of this study are available from the corresponding author on reasonable request.

\section{Conflict of interest}

The authors declare that they have no known competing financial interests or personal relationships that could have appeared to influence the work reported in this paper.

\section{Open Access}

This article is licensed under a Creative Commons Attribution 4.0 International License, which permits use, sharing, adaptation, distribution and reproduction in any medium or format, as long as you give appropriate credit to the original author(s) and the source, provide a link to the Creative Commons licence, and indicate if changes were made. The images or other third party material in this article are included in the article's Creative Commons licence, unless indicated otherwise in a credit line to the material. If material is not included in the article's Creative Commons licence and your intended use is not permitted by statutory regulation or exceeds the permitted use, you will need to obtain permission directly from the copyright holder. To view a copy of this licence, visit http://creativecommons.org/licenses/by/4.0/. 


\section{References}

1. M. Orme, I. Madera, M. Gschweitl, and M. Ferrari, Topology Optimization for Additive Manufacturing as an Enabler for Light Weight Flight Hardware, Designs., 2018, 2, p 51. https://doi.org/10. 3390/designs 2040051

2. C. Yan, L. Hao, A. Hussein, P. Young, J. Huang, and W. Zhu, Microstructure and Mechanical Properties of Aluminium Alloy Cellular Lattice Structures Manufactured by Direct Metal Laser Sintering, Mater. Sci. Eng. A., 2015, 628, p 238-246. https://doi.org/10.1016/j. msea.2015.01.063

3. L. Thijs, K. Kempen, J.P. Kruth, and J. Van Humbeeck, Fine-Structured Aluminium Products with Controllable Texture by Selective Laser Melting of Pre-Alloyed AlSi10Mg Powder, Acta Mater, 2013, 61, p 1809-1819. https://doi.org/10.1016/j.actamat.2012.11.052

4. X. Liu, C. Zhao, X. Zhou, Z. Shen, and W. Liu, Microstructure of Selective Laser Melted AlSi10Mg Alloy, Mater. Des., 2019, 168, p 107677. https://doi.org/10.1016/j.matdes.2019.107677

5. J. Fiocchi, A. Tuissi, P. Bassani, and C.A. Biffi, Low Temperature Annealing Dedicated to AlSi10Mg Selective Laser Melting Products, $J$. Alloys Compd., 2017, 695, p 3402-3409. https://doi.org/10.1016/j.jallc om.2016.12.019

6. N.T. Aboulkhair, C. Tuck, I. Ashcroft, I. Maskery, and N.M. Everitt, On the precipitation hardening of selective laser melted AlSi10Mg, metall. Mater. Trans. A Phys. Metall. Mater. Sci., 2015, 46, p $3337-$ 3341. https://doi.org/10.1007/s11661-015-2980-7

7. M.T. Di Giovanni, J.T.O. de Menezes, G. Bolelli, E. Cerri, and E.M. Castrodeza, Fatigue crack growth behavior of a selective laser melted AlSi10Mg, Eng. Fract. Mech., 2019, 217, p 106564. https://doi.org/10. 1016/j.engfracmech.2019.106564

8. Y. Kok, X.P. Tan, P. Wang, M.L.S. Nai, N.H. Loh, E. Liu, and S.B. Tor, Anisotropy and Heterogeneity of Microstructure and Mechanical Properties in Metal Additive Manufacturing: A Critical Review, Mater. Des., 2018, 139, p 565-586. https://doi.org/10.1016/j.matdes.2017.11. 021

9. M. Tang, and P.C. Pistorius, Anisotropic Mechanical Behavior of alsi10mg Parts Produced by Selective Laser Melting, Jom., 2017, 69, p 516-522. https://doi.org/10.1007/s11837-016-2230-5

10. D. Herzog, V. Seyda, E. Wycisk, and C. Emmelmann, Additive Manufacturing of Metals, Acta Mater., 2016, 117, p 371-392. https://d oi.org/10.1016/j.actamat.2016.07.019

11. L. Hitzler, C. Janousch, J. Schanz, M. Merkel, B. Heine, F. Mack, W. Hall, and A. Öchsner, Direction and Location Dependency of Selective Laser Melted AlSi10Mg Specimens, J. Mater. Process. Technol., 2017, 243, p 48-61. https://doi.org/10.1016/j.jmatprotec.2016.11.029

12. J.T. Oliveira de Menezes, E.M. Castrodeza, and R. Casati, Effect of Build Orientation on Fracture and Tensile Behavior of A357 Al Alloy Processed by Selective Laser Melting, Mater. Sci. Eng. A., 2019, 766, p 138392. https://doi.org/10.1016/j.msea.2019.138392

13. J.H. Rao, Y. Zhang, K. Zhang, X. Wu, and A. Huang, Huang, Huang, Selective Laser Melted Al-7Si-06Mg Alloy with In-Situ Precipitation Via Platform Heating for Residual Strain Removal, Mater. Des., 2019, 182, p 108005. https://doi.org/10.1016/j.matdes.2019.108005

14. B.E. Carroll, T.A. Palmer, and A.M. Beese, Anisotropic Tensile Behavior of Ti-6Al-4V Components Fabricated with Directed Energy Deposition Additive Manufacturing, Acta Mater., 2015, 87, p 309-320. https://doi.org/10.1016/j.actamat.2014.12.054

15. M. Simonelli, Y.Y. Tse, and C. Tuck, Effect of the Build Orientation on the Mechanical Properties and Fracture Modes of SLM Ti-6Al-4V, Mater. Sci. Eng. A., 2014, 616, p 1-11. https://doi.org/10.1016/j.msea. 2014.07.086

16. L. Hitzler, J. Hirsch, B. Heine, M. Merkel, W. Hall, and A. Öchsner, On the Anisotropic Mechanical Properties of Selective Laser-Melted Stainless Steel, Mater (Basel), 2017 https://doi.org/10.3390/ma10101 136

17. A. Takaichi, Y. Kajima, N. Kittikundecha, H.L. Htat, H.H. Wai Cho, T. Hanawa, T. Yoneyama, N. Wakabayashi, Effect of Heat Treatment on the Anisotropic Microstructural and Mechanical Properties of $\mathrm{Co}-\mathrm{Cr}-$ Mo Alloys Produced by Selective Laser Melting, J. Mech. Behav. Biomed. Mater. 102 (2020). https://doi.org/10.1016/j.jmbbm.2019.10 3496

18. A. Hadadzadeh, B.S. Amirkhiz, J. Li, A. Odeshi, and M. Mohammadi, Deformation Mechanism During Dynamic Loading of an Additively Manufactured AlSi10Mg_200C, Mater. Sci. Eng. A., 2018, 722, p 263268. https://doi.org/10.1016/j.msea.2018.03.014
19. I. Rosenthal, A. Stern and N. Frage, Strain Rate Sensitivity and Fracture Mechanism of AlSi10Mg Parts Produced by Selective Laser Melting, Mater. Sci. Eng. A., 2017, 682, p 509-517. https://doi.org/10. 1016/j.msea.2016.11.070

20. T. Maconachie, M. Leary, J. Zhang, A. Medvedev, A. Sarker, D. Ruan, G. Lu, O. Faruque, and M. Brandt, Effect of Build Orientation on the Quasi-Static and Dynamic Response of SLM AlSi10Mg, Mater. Sci. Eng. A., 2020, 788, p 139445. https://doi.org/10.1016/j.msea.2020.13 9445

21. L. Girelli, M. Giovagnoli, M. Tocci, A. Pola, A. Fortini, M. Merlin, and G.M. La Vecchia, Evaluation of the Impact Behaviour of AlSi10Mg Alloy Produced Using Laser Additive Manufacturing, Mater. Sci. Eng. A., 2019, 748, p 38-51. https://doi.org/10.1016/j.msea.2019.01.078

22. M. Giovagnoli, M. Tocci, A. Fortini, M. Merlin, M. Ferroni, A. Migliori, and A. Pola, Effect of Different Heat-Treatment Routes on the Impact Properties of an Additively Manufactured AlSi10Mg Alloy, Mater. Sci. Eng. A., 2021, 802, p 140671. https://doi.org/10.1016/j. msea.2020.140671

23. EOS Aluminium AlSi10Mg Material Data Sheet, n.d. https://www.g oogle.com/url?q=https://www.eos.info/03_system-related-assets/materi al-related-contents/metal-materials-and-examples/metal-material-datas heet/aluminium/material datasheet eos aluminium-alsi10mg en web. pdf\&sa $=$ D\&source $=$ editors\&ust $=1 \overline{6} 31692284086$

24. S. Hafenstein, M. Brummer, M. Ahlfors, and E. Werner, Combined Hot Isostatic Pressing and Heat Treatment of Aluminum A356 Cast Alloy, HTM J. Heat Treat. Mater., 2016, 71, p 117-124.

25. E. Lucon, Experimental Assessment of the Equivalent Strain Rate for an Instrumented Charpy Test, J. Res. Natl. Inst. Stand. Technol., 2016, 121, p 165-179. https://doi.org/10.6028/jres.121.007

26. N. Liang, Y. Zhao, J. Wang, and Y. Zhu, Effect of Grain Structure on Charpy Impact Behavior of Copper, Sci. Rep., 2017, 7, p 1-11. https://d oi.org/10.1038/srep44783

27. C.A. Schneider, W.S. Rasband, and K.W. Eliceiri, NIH Image to ImageJ: 25 Years of Image Analysis, Nat. Methods., 2012, 9, p 671675 .

28. V. Consonni, G. Rey, H. Roussel, B. Doisneau, E. Blanquet, and D. Bellet, Preferential Orientation of Fluorine-Doped SnO 2 Thin Films: The Effects of Growth Temperature, Acta Mater., 2013, 61, p 22-31. h ttps://doi.org/10.1016/j.actamat.2012.09.006

29. H.R. Moutinho, F.S. Hasoon, F. Abulfotuh, L.L. Kazmerski, H.R. Moutinho, F.S. Hasoon, F. Abulfotuh, L.L. Kazmerski 2013 Investigation of Polycrystalline CdTe Thin Films Deposited by Physical Vapor Deposition, Closespaced Sublimation, and Sputtering Investigation of Polycrystalline CdTe Thin Films Deposited by Physical Vapor Deposition , close-spaced sublimation, and spu. https://doi.org/ $10.1116 / 1.579607$

30. L. Lutterotti, H.R. Wenk, S. Matthies, MAUD (Material Analysis Using Diffraction): a User Friendly Java Program for Rietveld Texture Analysis and More, In: ICOTOM-12., 1999: pp. 1599-1604

31. T. Maeshima, and K. Oh-ishi, Solute Clustering and Supersaturated Solid Solution of AlSi10Mg Alloy Fabricated by Selective Laser Melting, Heliyon., 2019, 5, p e01186. https://doi.org/10.1016/j.heliyon. 2019.e 01186

32. S. Marola, D. Manfredi, G. Fiore, M.G. Poletti, M. Lombardi, P. Fino, and L. Battezzati, A Comparison of Selective Laser Melting with Bulk Rapid Solidification of AlSi10Mg Alloy, J. Alloys Compd., 2018, 742, p 271-279. https://doi.org/10.1016/j.jallcom.2018.01.309

33. L. Zhou, A. Mehta, E. Schulz, B. McWilliams, K. Cho, and Y. Sohn, Microstructure, Precipitates and Hardness of Selectively Laser Melted AlSi10Mg Alloy Before and After Heat Treatment, Mater. Charact., 2018, 143, p 5-17. https://doi.org/10.1016/j.matchar.2018.04.022

34. Y.K. Xiao, Z.Y. Bian, Y. Wu, G. Ji, Y.Q. Li, M.J. Li, Q. Lian, Z. Chen, A. Addad, and H.W. Wang, Effect of Nano-TiB2 Particles on the Anisotropy in an AlSi10Mg Alloy Processed by Selective Laser Melting, J. Alloys Compd., 2019, 798, p 644-655. https://doi.org/10. 1016/j.jallcom.2019.05.279

35. A.H. Maamoun, M. Elbestawi, G.K. Dosbaeva, and S.C. Veldhuis, Thermal Post-Processing of AlSi10Mg Parts Produced by Selective Laser Melting Using Recycled Powder, Addit. Manuf., 2018, 21, p 234-247. https://doi.org/10.1016/j.addma.2018.03.014

36. A. Hadadzadeh, B.S. Amirkhiz, and M. Mohammadi, Contribution of $\mathrm{Mg} 2 \mathrm{Si}$ Precipitates to the Strength of Direct Metal Laser Sintered AlSi10Mg, Mater. Sci. Eng. A., 2019, 739, p 295-300. https://doi.org/ 10.1016/j.msea.2018.10.055 
37. N. Takata, H. Kodaira, K. Sekizawa, A. Suzuki, and M. Kobashi, Change in Microstructure of Selectively Laser Melted AlSi10Mg Alloy with Heat Treatments, Mater. Sci. Eng. A., 2017, 704, p 218-228. h ttps://doi.org/10.1016/j.msea.2017.08.029

38. F. Alghamdi, X. Song, A. Hadadzadeh, B. Shalchi-Amirkhiz, M. Mohammadi, and M. Haghshenas, Post heat Treatment of Additive Manufactured AlSi10Mg: On Silicon Morphology, Texture and SmallScale Properties, Mater. Sci. Eng. A., 2020, 783, p 139296. https://doi. org/10.1016/j.msea.2020.139296

39. L. Thijs, M.L. Montero Sistiaga, R. Wauthle, Q. Xie, J.P. Kruth, and J. Van Humbeeck, Strong Morphological and Crystallographic Texture and Resulting Yield Strength Anisotropy in Selective Laser Melted Tantalum, Acta Mater., 2013, 61, p 4657-4668. https://doi.org/10.101 6/j.actamat.2013.04.036

40. M. Diehl, J. Niehuesbernd, and E. Bruder, Quantifying the Contribution of Crystallographic Texture and Grain Morphology on the Elastic and Plastic Anisotropy of bcc Steel, Metals (Basel)., 2019, 9, p 1-21. h ttps://doi.org/10.3390/met9121252

41. W.F. Hosford, Mechanical Behavior of Materials, Cambridge University Press, 2010

42. E. Schmid, and W. Boas, Plasticity of crystals with special reference to metals, F.A. Hughes \& Co, 1935

43. Y.J. Liu, Z. Liu, Y. Jiang, G.W. Wang, Y. Yang, and L.C. Zhang, Gradient in Microstructure and Mechanical Property of Selective Laser Melted AlSi10Mg, J. Alloys Compd., 2018, 735, p 1414-1421. http s://doi.org/10.1016/j.jallcom.2017.11.020
44. A. Hadadzadeh, B. ShalchiAmirkhiz, A. Odeshi, J. Li, and M. Mohammadi, Role of Hierarchical Microstructure of Additively Manufactured AlSi10Mg on Dynamic Loading Behavior, Addit. Manuf., 2019, 28, p 1-13. https://doi.org/10.1016/j.addma.2019.04.012

45. L. Zhao, J.G. Santos Macías, L. Ding, H. Idrissi, and A. Simar, Damage Mechanisms in Selective Laser Melted AlSi10Mg Under as Built and Different Post-Treatment Conditions, Mater. Sci. Eng. A., 2019, 764, p 1-25. https://doi.org/10.1016/j.msea.2019.138210

46. D. Broek, The Role of Inclusions in Ductile Fracture and Fracture Toughness, Eng. Fract. Mech., 1973, 5, p 55-66. https://doi.org/10. 1016/0013-7944(73)90007-6

47. U. Patakham, A. Palasay, P. Wila and R. Tongsri, MPB Characteristics and Si Morphologies on Mechanical Properties and Fracture Behavior of SLM AlSi10Mg, Mat. Sci. Eng. A, 2021, 821, p 141602. https://doi. org/10.1016/j.msea.2021.141602

48. Z.H. Xiong, S.L. Liu, S.F. Li, Y. Shi, Y.F. Yang, and R.D.K. Misra, Role of Melt Pool Boundary Condition in Determining the Mechanical Properties of Selective Laser Melting AlSi10Mg Alloy, Mat Sci Eng A, 2019, 740-741, p 148-156. https://doi.org/10.1016/j.msea.2018.10.08

Publisher's Note Springer Nature remains neutral with regard to jurisdictional claims in published maps and institutional affiliations. 